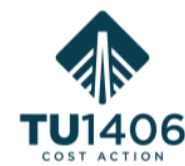

\title{
Application of Bridge Weigh-in-Motion measurements in assessment of existing road bridges
}

\author{
Dominik Skokandić ${ }^{1}$, Aleš Žnidarič², \\ Ana Mandić-Ivanković3 ${ }^{3}$, Maja Kreslin ${ }^{4}$
}

\author{
DOI: https://doi.org/10.5592/CO/BSHM2017.4.6 \\ ${ }^{1,3}$ University of Zagreb, Faculty of Civil Engineering, Kačićeva 26, 10000 Zagreb, Croatia \\ ${ }^{2,4}$ Slovenian National Building and Civil Engineering Institute, Dimičeva ulica 12, 1000 Ljubljana, Slovenia \\ E-mails: ${ }^{1}$ dskokandic@grad.hr ; ${ }^{2}$ ales.znidaric@zag.si; ${ }^{1}$ mandicka@grad.hr $;{ }^{2}$ maja.kreslin@zag.si
}

\begin{abstract}
Application of current European standards (Eurocode) for the design of new bridges in assessment of existing ones proved non-efficient due to conservative assumptions regarding applied load and subsequent response of these bridges. That is why decisions regarding existing bridges should be based on probabilistic approach, combining advanced methods of analysis with real values and data gathered with on-site measurement and laboratory testing. These types of data are gathered trough Structural Health Monitoring tools as it allows us to observe and record various data over a period of time in order to estimate bridge current condition and to track eventual changes in its behavior. Bridge Weigh-in-Motion measurements, as a part of structural health monitoring of existing bridges, provide us with detailed information regarding volume and weight of traffic on the bridge, while also tracking its structural response. Site specific load models for examined bridges can be developed from collected traffic data, using various extrapolation methods. Simple and fast, and yet precise method of traffic data processing is presented in first part of this paper, while its application, along with bridge structural response data, in optimized bridge assessment is presented in the second part of the paper.
\end{abstract}

Keywords: optimized bridge assessment, bridge weigh-in-motion, site specific traffic load models.

\section{Introduction}

Current standards and codes for design of new bridges are based on conservative assumptions regarding load and resistance modelling in order to be applicable on different bridge types. Although those codes result in creation of safe and cost-effective new bridges, use of same standards for assessment of existing bridges may show that many of these bridges need to be strengthened or even replaced (Wiśniewski et al. 2012; Šavor \& Novak 2015; Žnidarič et al. 2016). Available standards for existing bridges are less conservative, but are also general, while research showed that site specific bridge assessment, based on measured traffic, can lead to reduction in maintenance costs and extension of remaining service life of specified bridges (Žnidarič et al. 2012; Žnidarič et al. 2016).

Weigh-in-Motion (WIM) (Žnidarič et al. 2016)is a procedure that measures axle weight and gross weights as a vehicle drives over measurement site in full speed, without the need for slowing down or stopping. Stationary WIM systems today apply sensors built into the pavement, with exception of bridge based WIM systems, called Bridge Weigh-in-Motion (B-WIM), which use instrumented bridges as weighing scales. Main advantage over the stationary WIM systems is that they are fully portable, and during installation and maintenance they do not interfere with traffic flow (Žnidarič et al. 2012). Data collected with WIM measurements can be used for a number of applications such as traffic analyses, pavement and bridge design and/or assessment, selection of overloaded vehicles, etc. Site-specific traffic load models, developed from WIM data, are a key input for optimized assessment of existing bridges (Žnidarič et al. 2016). Development of site specific traffic load models using simple and fast method proposed in (Žnidarič et al. 2012) is presented in the chapter 2.

Data gathered with B-WIM measurements also provides realistic structural response of the bridge, which can be used to improve numerical models used in analysis. These types of data enable us to optimize load carrying capacity assessment, as it can be used to discover any type of degradation (even those non visible), such as cracking, which will affect transverse load distributions. Furthermore, realistic support conditions, which can have significant effect on bridge internal forces and bending moments, are also provided with B-WIM measurements. Application of B-WIM data in optimization of numerical bridge models is described in chapter 3 . 


\section{Post processing of B-WIM data}

The main challenge in development of site-specific load models is extrapolation of measured WIM data, and consequently, accurate estimation of the maximum load effect on a bridge (bending moments and shears) in certain time period/bridge lifetime. There are number of proposed methods, based either on fitting statistical distribution to the calculated on collected data or using simulations, such as Monte Carlo method to extrapolate limited traffic information. Method used in this paper is suitable for short and medium span bridges, with independent traffic lanes, and is proposed in (Žnidarič et al. 2012). It is based on convolution method (Sivakumar et al. 2011; Žnidarič \& Moses 1997) and an assumption that highest load effect is achieved when two trucks from independent traffic flows are placed on the bridge side by side in each traffic lane, at the place of maximum action, what is defined as a loading event. Calculation of load effects of each vehicle passing the bridge, from data obtained with B-WIM measurements, is conducted using the influence lines method, where results are presented in terms of maximum expected moments and shear forces of the critical part of the bridge for a specified time period. Proposed method is based on the one proposed by Moses and Verma in (Moses \& Verma 1987), and can be divided in five steps presented in sections 2.1. -2.5 .

\subsection{Collection of B-WIM data}

B-WIM measurements provide multiple parameters for every vehicle passing the bridge, including timestamp and lane position of every vehicle passage, gross weight, weight of every axle, axle number and spacing etc. In measurement process, vehicles weighing less than 3,5 tones are not taken into account, as they have very low impact on bridge performance and assessment. Every vehicle that is not classified automatically by the software can be manually checked and placed in the right class. Typical data acquired from B-WIM measurement is presented in Table 1 (only as an example, a single pass of two axle truck is showed).

Table 1 - B-WIM output example

\begin{tabular}{c|c|c|c|c|c|c|c|c}
\hline Time stamp & Lane & $\begin{array}{c}\text { Speed } \\
{[\mathbf{m} / \mathbf{s}]}\end{array}$ & Class & $\begin{array}{c}\text { Number } \\
\text { of axles }\end{array}$ & $\begin{array}{c}\text { GSW } \\
{[\mathbf{k N}]}\end{array}$ & $\begin{array}{c}\text { AW1 } \\
{[\mathbf{k N}]}\end{array}$ & $\begin{array}{c}\text { AW2 } \\
{[\mathbf{k N}]}\end{array}$ & $\begin{array}{c}\text { Axle spacing } \\
{[\mathbf{m}]}\end{array}$ \\
\hline $2007-03-22-00-39-28-955$ & 1 & 17,5 & 41 & 2 & 123,8 & 37,07 & 86,69 & 6,07 \\
\hline
\end{tabular}

Collection of traffic data is conducted using commercial B-WIM system SiWIM (Žnidarič et al. 2011), developed in Slovenia as an outcome of COST 323(Jacob et al. 2002) action and EC $4^{\text {th }}$ Framework project Wave (Jacob 2002).

\subsection{Calculation of load effects}

Calculation of load effects (bending and shear at critical bridge sections) is conducted using bridge influence lines. Theoretical influence lines for bending and shear of the bridge are easily created, depending on a bridge span and support conditions. B-WIM measurements also can provide realistic influence lines (Žnidarič et al. 2010), which can differ from theoretical ones (due to age and deterioration of bridge bearings etc.) and would result in lower values of traffic effects (described in detail in chapter 3). Static load effect of each vehicle is defined with:

$$
Q_{s}=\sum_{i=1}^{n} A_{i} \cdot I_{i}
$$

where:

$A_{i} \quad$ is weight of the axle $i$,

$n \quad$ is number of axles of each vehicle,

$I_{i} \quad$ is value of the influence line due to the axle $i$ at location $x$

Example of calculated static load values for two vehicles is given in Table 2, where vehicles are presented with axle number $(\mathrm{n})$, weights $\left(\mathrm{W}_{\mathrm{i}}\right)$, spacing $\left(\mathrm{A}_{\mathrm{i}, \mathrm{i}+1}\right)$ and maximum static load effect (bending $\mathrm{M}_{\mathrm{Max}}$ and shear $\mathrm{V}_{\mathrm{Max}}$ ) with associated axle positions $\left(\mathrm{x}_{\mathrm{i}}, \mathrm{M}\right.$ and $\left.\mathrm{x}_{\mathrm{i}, \mathrm{V}}\right)$.

Table 2 - Calculated values of bending and shear for single vehicle

\begin{tabular}{|c|c|c|c|c|c|c|c|c|c|c|c|c|c|}
\hline $\mathrm{n}$ & $\begin{array}{c}\text { W1 } \\
{[\mathrm{kN}]}\end{array}$ & $\begin{array}{c}\text { W2 } \\
{[\mathrm{kN}]}\end{array}$ & $\begin{array}{c}\text { W3 } \\
{[\mathrm{kN}]}\end{array}$ & $\begin{array}{l}\mathbf{A}_{1-2} \\
{[\mathbf{m}]}\end{array}$ & $\begin{array}{l}\mathbf{A}_{2-3} \\
{[\mathbf{m}]}\end{array}$ & $\begin{array}{c}\mathbf{M}_{\text {Max }} \\
{[\mathrm{kNm}]}\end{array}$ & $\begin{array}{l}\mathbf{x}_{\mathbf{1 , M}} \\
{[\mathbf{m}]}\end{array}$ & $\begin{array}{l}\mathbf{x}_{2, \mathbf{M}} \\
{[\mathbf{m}]}\end{array}$ & $\begin{array}{l}\mathbf{x}_{3, \mathbf{M}} \\
{[\mathbf{m}]}\end{array}$ & $\begin{array}{l}\mathbf{V}_{\text {Max }} \\
\text { [kN] }\end{array}$ & $\begin{array}{l}\mathbf{x}_{1, \mathbf{v}} \\
{[\mathbf{m}]}\end{array}$ & $\begin{array}{l}\mathbf{x}_{2, \mathbf{v}} \\
{[\mathbf{m}]}\end{array}$ & $\begin{array}{l}\mathbf{x}_{\mathbf{3}, \mathbf{V}} \\
{[\mathbf{m}]}\end{array}$ \\
\hline 3 & 46,18 & 52,37 & 42,85 & 6,04 & 1,26 & 143,78 & 11,55 & 5,51 & 4,25 & 72,21 & 6,15 & 0,11 & 0,00 \\
\hline 2 & 37,07 & 86,69 & I & 6,07 & I & 237,62 & 11,55 & 5,48 & I & 102,39 & 6,15 & 0,08 & I \\
\hline
\end{tabular}



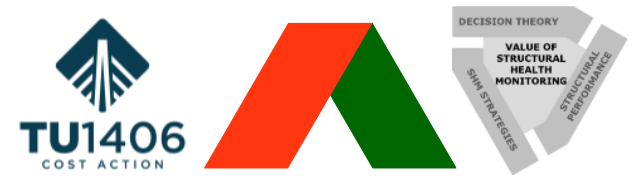

As total amount of vehicles data collected with B-WIM measurements is very large (it depends on the measurement duration, traffic flow and volume), theirs static values $\left(\mathrm{Q}_{\mathrm{s}}\right)$ are combined into histogram showed on Figure 1 (same procedure is the same for shear force values, but due to the length of the paper it is not presented), separately for each lane. Load intervals (bins) on $\mathrm{x}$ axis must be small enough to provide good resolution of the relative frequency histograms. Minimal number of bins is not strictly defined, but 60 to 100 intervals should provide sufficient quality of histograms for further calculations. Furthermore, abscissa must cover values at least $10 \%$ above the maximum calculated load effects in order to model the tails of distributions, according to (Žnidarič et al. 2012).

LANE 1

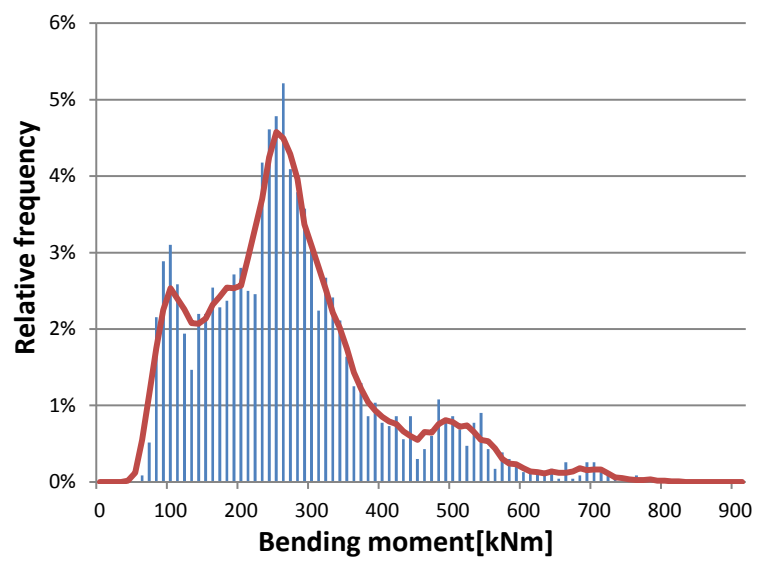

LANE 2

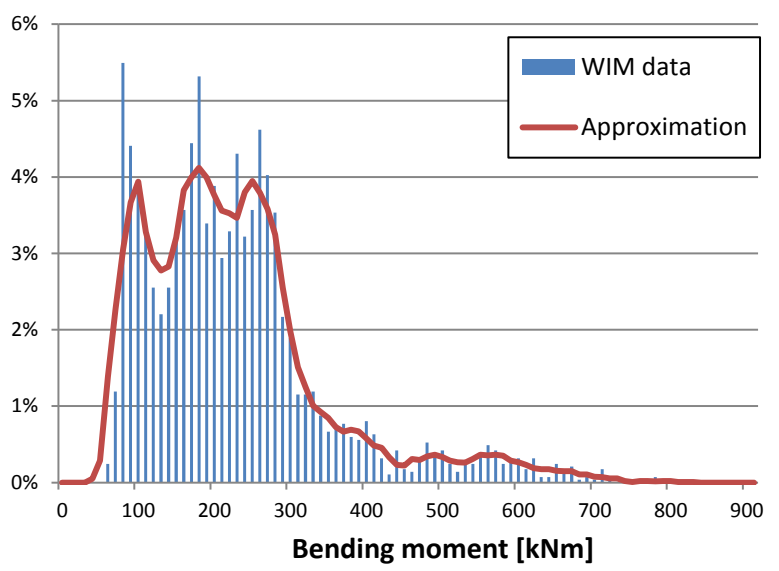

Figure 1 - Relative frequency histograms of bending moments for each lane

In order to smooth distribution curve and to extend it beyond the measured values, as extreme load events are infrequent (Figure 1), modified "moving average" approximation is applied on histograms. This approximation averages the selected number of values before and after averaged value, and is shown on Figure 1 with thick red line. Number of points to average depends on the reliability of traffic information, and can go up to \pm 10 , but in this example \pm 3 points are used.

\subsection{Generation of load effects histograms}

Next step in presented procedure is convolution of histograms for each lane to simulate loading effect for an event comprised of vehicles from both lanes, which will be presented with probability mass function (PMF) and the corresponding cumulative distribution function (CDF).

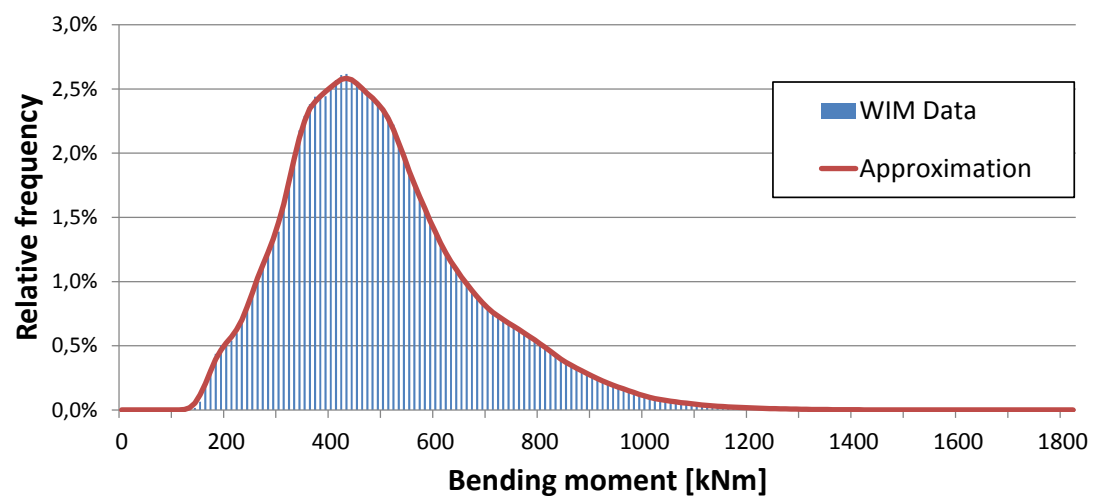

Figure 2 - Probability mass functions for loading event (bending moment)

As distributions of load effects for lanes 1 and 2 are independent, as we assumed before that traffic in one lane does not affect other, PMF of event for both lanes is defined as:

$$
f_{z}=\sum_{k=1}^{m} f_{x}(k) \cdot f_{y}(z-k)
$$


where $f_{\mathrm{x}}$ and $f_{\mathrm{y}}$ are PMFs (approximated histograms) of load effects for lanes 1 and 2, and $f_{z}$ is the PMF of the load effects for an event comprising vehicles in each lane (Figure 2). As X and Y are independent and its PMFs $f_{\mathrm{x}}$ and $f_{\mathrm{y}}$ have $m$ bins, $\mathrm{Z}$ equals to $(\mathrm{X}+\mathrm{Y})$ and $f_{z}$ has the length of $(2 \cdot m-1)$ bins.

\subsection{Cumulative distribution functions and maximum load effects}

Cumulative distribution function (also called convolution curve (Žnidarič et al. 2012)) for a single loading event $F_{Z}$ is derived from PDF on Figure 2. Expected maximum load effects $F_{\max }$ for different time periods are created using extreme value theory (Ang \& Tang 1975):

$$
F_{\text {max }}(z)=F_{z}^{N}(z)
$$

where $N$ is number of expected multiple presence events (when vehicles from both lanes meet on the critical section of the bridge) in associated time period. Convolution curves for bending moments, for different time periods, are presented on Figure 3. Evaluation of expected loading events $N$ is described in the following section.

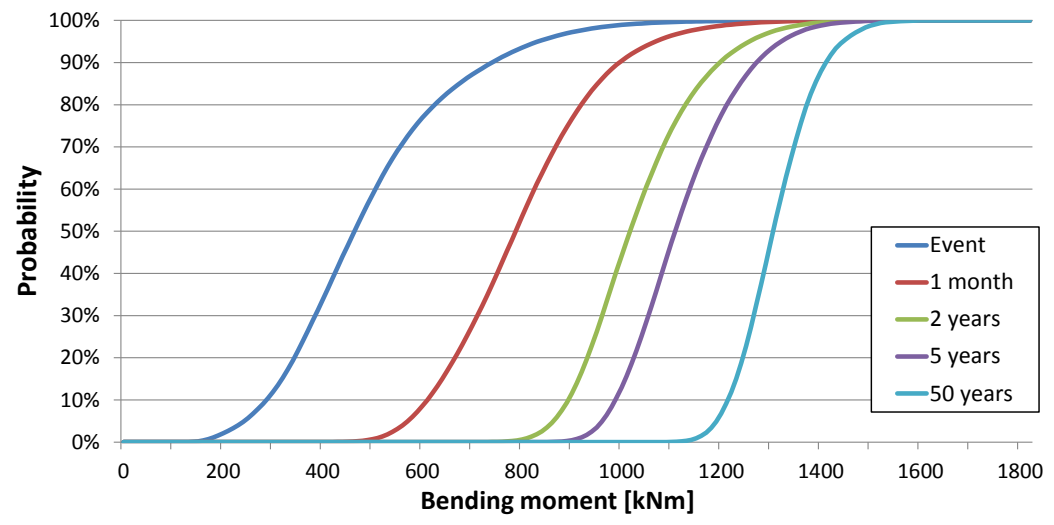

Figure 3 - Convolution curves for maximum bending moment in relevant time periods

Median and characteristic values of function $F_{\max }$ are easily calculated from convolution curves, while total predicted maximum load effects

$$
Q=Q_{S} \cdot D A F \cdot g
$$

where $Q_{\mathrm{S}}$ is static load effect from Equation 1, DAF is dynamic amplification factor, representing the dynamic amplification of the traffic loading, and $g$ is girder distribution factor that represents proportion of total traffic load carried out by a critical cross section under analysis. Detailed information on calculation and proper selection of $D A F$ and $g$ values can be found in (Žnidarič et al. n.d.). Mean values $(\mathrm{m})$ and standard deviations $(\sigma)$ for maximum expected load effects are derived from convolution curves on Figure 3 and presented in the Table 3. Upper and lower characteristic values (5\% and $95 \%$ quantiles) can be easily calculated with the same procedure (Žnidarič et al. 2012).

Table 3 - Statistic parameters of maximum expected load effects

\begin{tabular}{c|c|c}
\hline Time period & Mean value $[\mathbf{k N m}]$ & Standard deviation $[\mathbf{k N m}]$ \\
\hline Single event & 463,60 & 169,65 \\
\hline One month & 922,14 & 125,72 \\
\hline Two years & 1016,96 & 116,97 \\
\hline Five years & 1107,48 & 115,54 \\
\hline Fifty years & 1304,17 & 76,06 \\
\hline
\end{tabular}

\subsection{Selection of proper number of expected events $N$}

Number of expected multiple presence events $N$ directly affects maximum expected traffic loading on the bridge, in selected time period. As more multiple presence events occur on the bridge higher will be maximum load effect in selected time period. There are two approaches to calculate, generating headway histograms (Moses \& Verma 1987) and gaps between vehicles, or deriving $N$ directly from WIM data sample (if time stamp is provided to at least $1 / 100$ of a second) (Žnidarič et al. 2012). In this example we use the latter, but due to the length of the paper it is not presented in detail, but can be found in (Žnidarič et al. 2012). 

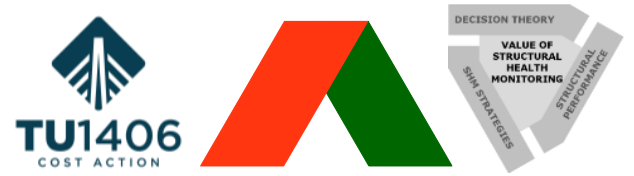

The Value of Structural Health Monitoring for the reliable Bridge Management

Zagreb 2-3 March 2017

\section{Application of B-WIM in assessment of exiting road bridges}

Assessment of existing bridges using detailed numerical models of those bridges is very common approach in order to determine its load distribution, modal shapes, deflections and other bridge parameters that are needed to establish its load carrying capacity. These models are mainly developed using Finite Elements Method (FEM), and when original design plans are available, they can be developed to a very precise level, even with taking into account certain amount of degradation trough time.

Nevertheless, without data from on-site measurements and monitoring, it is very hard to simulate realistic behavior of existing bridge on its numerical model, as certain parameters are hard to determine only with visual inspection of the bridge. Along with determination of site specific load models, explained in previous chapter, BWIM measurements can also provide additional data, such as realistic influence lines and transverse load distributions. Combination of these additional parameters with numerical models of the bridge, developed in Sofistik software (SOFISTIK AG, 2014) for structural analysis, is presented in following sections with load carrying capacity assessment of Case Study Bridge (Skokandic 2016).

\subsection{Case Study Bridge}

Case Study Bridge is simply supported highway bridge with a single span of 24,8 meters, its superstructure is composed of five prefabricated I-type girders connected with a monolithic concrete deck (Figure 4). Original design plans, along with built in reinforcement, were available from the archives and 3D FEM model is developed in Sofistik and showed on Figure 5.

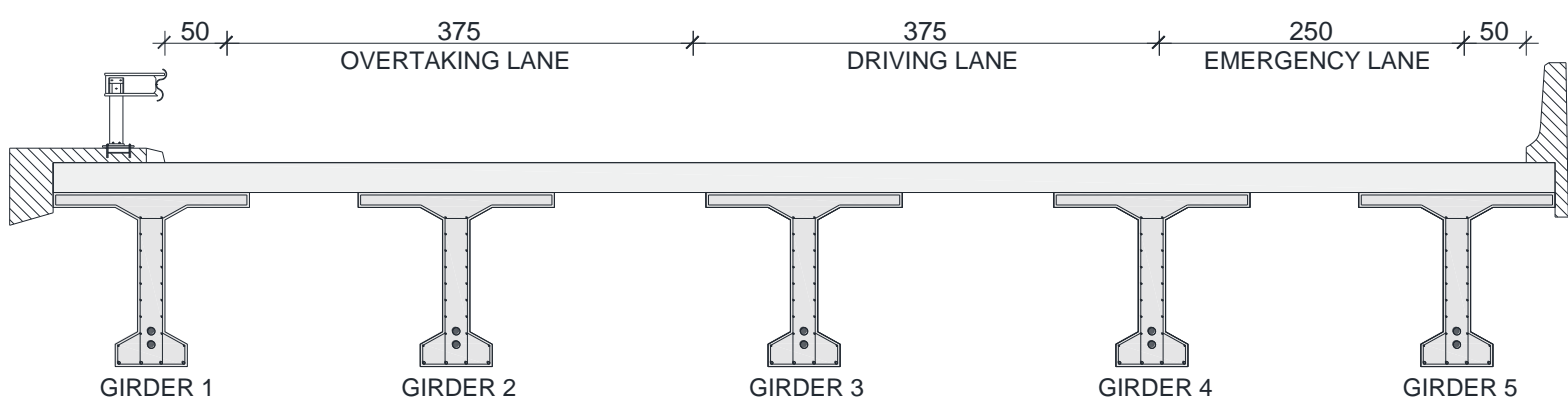

Figure 4 - Cross section of Case Study Bridge with built in reinforcement

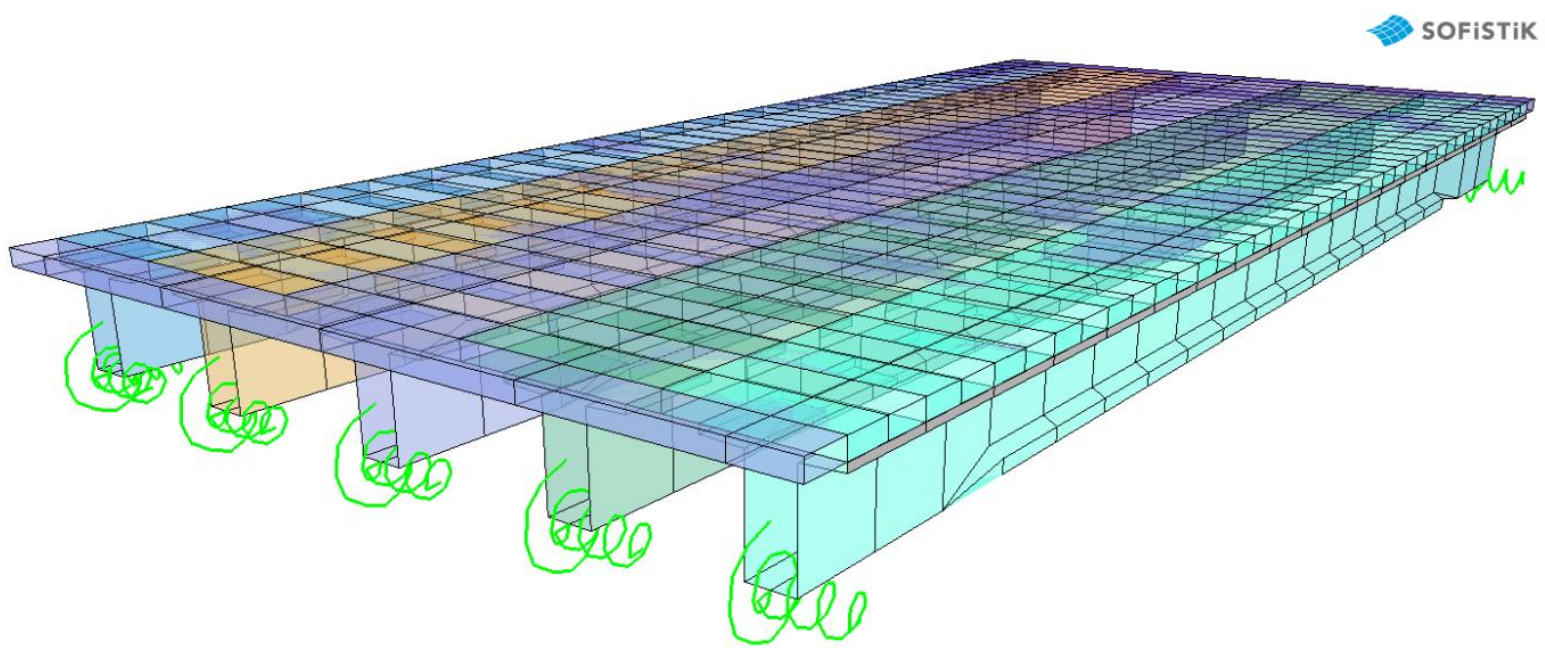

Figure 5 - 3D FEM model of Case Study Bridge

In initial step of the assessment procedure linear analysis was conducted, taking into account self - weight, additional permanent load and traffic load according to EN Load Model 1 (Eurocode 2004a). Bending moments at the middle of the span are calculated with load factors of 1,35 for all loads. Cross section resistance to bending is calculated using original design plans and built in reinforcement according to (Eurocode 2004b). Comparison 
of the results of initial assessment and the later steps, using B-WIM data, are presented in Table 4 at the end of the paper.

\subsection{Application of additional B-WIM data}

\subsubsection{Realistic Influence lines}

Based on the original design plans, bridge model is developed as simply supported single span bridge, with theoretical influence lines for bending moment in the middle of the span are showed on Figure 6.
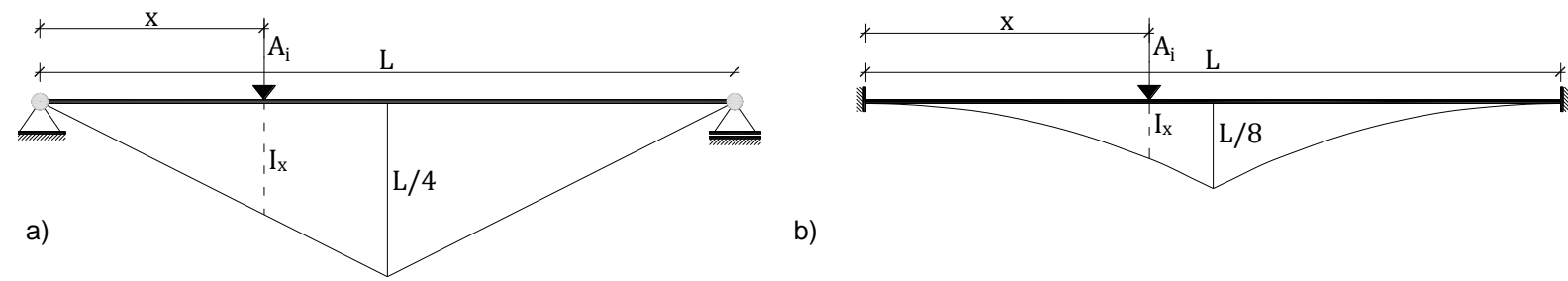

b)

Figure 6 - Theoretical Influence lines for simply supported (a) and fixed bridges (b) (Žnidarič et al. 2012)

As B-WIM technology uses influence lines to calculate static load effect of each passing vehicle (as described in section 2.2.), it has to be calibrated on every bridge before the measurements process begin. Calibration is performed with number of vehicles with familiar axle weight, spacing etc. in order to adjust the measuring sensors. As an output of calibration process measured (realistic) influence lines are obtained, which can differ from theoretical ones due to changes in bridge support conditions (O'Brien et al. 2008; Karoumi et al. 2006). Comparison of theoretical and measured influence lines for bending moment in the middle of the span for Case Study Bridge is showed on Figure 7.

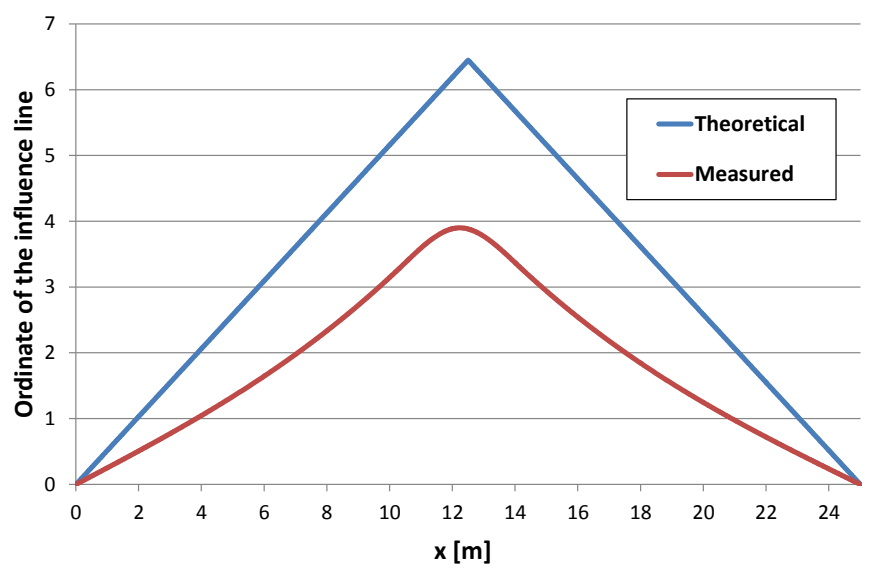

Figure 7 - Comparison of influence lines - Case Study Bridge

Measured influence line, showed above, revealed that realistic bridge behavior is not simply supported, and that the bridge is partially fixed on supports, probably due to degradation of bearings trough time. As a result, bending moments in the middle of the span are reduced compared to theoretical bridge model, adding to resistance/load ratio of bridge cross section.

\subsubsection{Transverse load distribution}

Distribution of total load on the bridge on its girders in basic numerical model is taken based on bridge cross section geometry and stiffness if the girders. As a part of B-WIM measurements, sensors in transverse direction are placed on every girder, providing its realistic deflection, which enables to determine amount of load taken by specific girder (Žnidarič et al. 2010).

These types of data reveal eventual differences between theoretical and realistic stiffness of bridge elements, pointing to some type of degradation, even those not visible, such as cracking of concrete element, yielding of reinforcement etc.

Figure 8 presents comparison of measured and theoretical load distribution factors (in percentages) for traffic load, showing that there is no significant difference in distribution. These results for Case Study Bridge were expected, due to no visible signs of degradation discovered during initial visual inspection. 

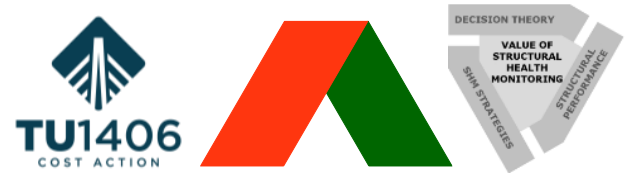

The Value of Structural Health Monitoring for the reliable Bridge Management

Zagreb 2-3 March 2017

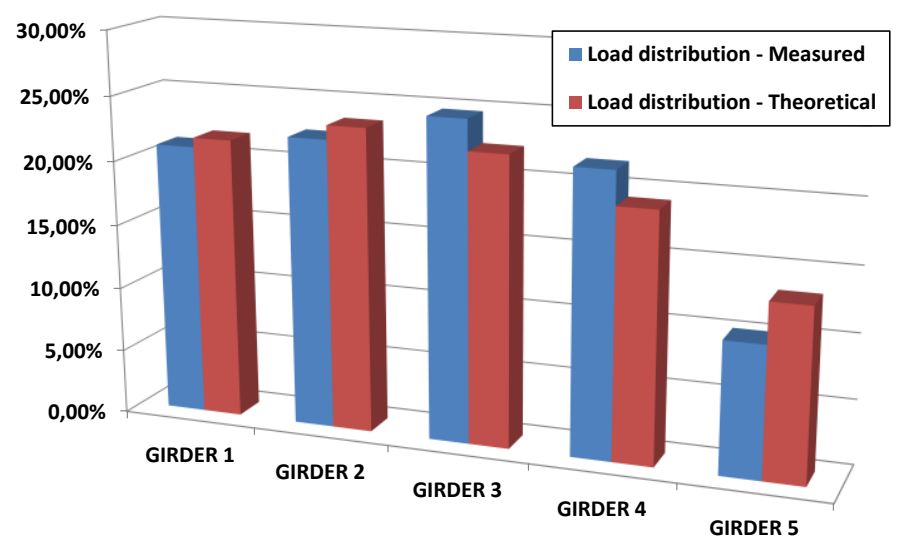

Figure 8 - Comparison of load distribution on each girder - Case Study Bridge

\subsubsection{Site-specific traffic load models}

Traffic load effects (bending moment in the middle of the span), determined from B-WIM data as explained in chapter 2, are applied on bridge model. Period of 75 years is chosen for extrapolation of available traffic data, as it represents remaining design service life of the bridge. Comparison of these traffic load effects with bending moments calculated in Sofistik using EN Load Model 1 (Eurocode 2004a) is presented in Figure 9.

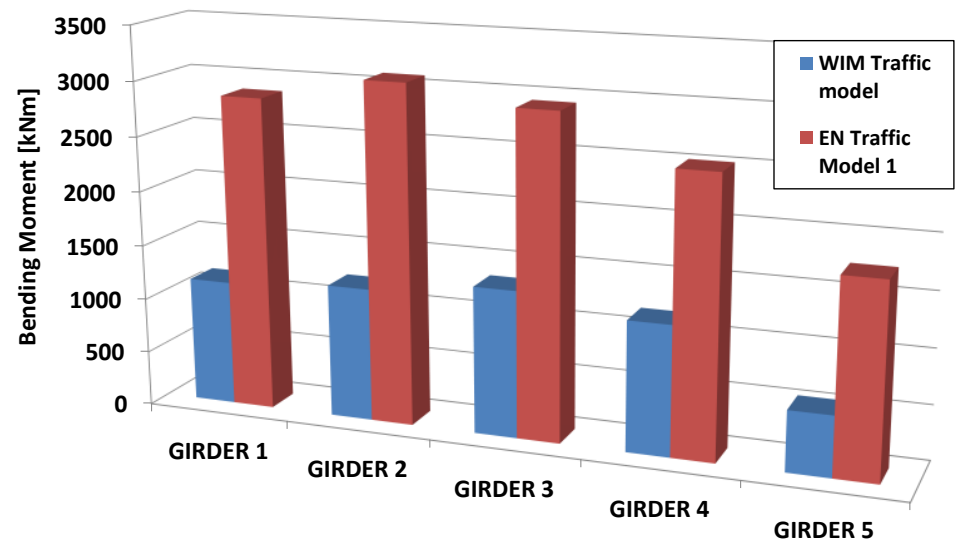

Figure 9-Comparison of traffic load effects - bending moment in the middle of the span

\subsection{Analysis of the results}

Results of load carrying capacity of Case Study Bridge using B-WIM data and standards for the design of new bridges are presented in Table 4, as a comparison of load/resistance ratio of every girder. Same analysis can also be conducted using probabilistic approach, as site-specific load effects are defined with statistical parameters, mean value and standard deviation.

Table 4 - Analysis of the results (Skokandić 2016)

\begin{tabular}{l|c|c|c|c|c}
\hline & Girder 1 & Girder 2 & Girder 3 & Girder 4 & Girder 5 \\
\hline $\begin{array}{l}\mathbf{M}_{\mathbf{R d}} / \mathbf{M}_{\mathbf{E d}}-\text { based on } \\
\text { current standards }\end{array}$ & 1,046 & 0,992 & 1,022 & 1,124 & 1,390 \\
\hline $\begin{array}{l}\mathbf{M}_{\mathbf{R d}} / \mathbf{M}_{\mathbf{E d}}-\text { based on } \\
\text { proposed method }\end{array}$ & 2,036 & 1,965 & 1,894 & 2,042 & 2,797 \\
\hline
\end{tabular}

As shown in the table above, application of B-WIM data resulted in reduced bending moment on the Case Study Bridge, increasing the resistance/load ratio for around $100 \%$. 


\section{Conclusion}

Results of Case Study Bridge assessment (Table 4) show how the classified by the current design standards as inadequate for use, because of insufficient resistance to bending of girder 2, bridge can be reassessed as safe with additional B-WIM data.

Economic aspect of this type of assessment can be defined as a comparison of initial investments in B-WIM measurements and reduction of bridge repair and maintenance costs as a result of more detailed bridge assessment.

Furthermore, beside the load carrying capacity assessment, WIM data can also be used for early discovery of non-visible degradations in bridge elements, as described in section 3.2.2.

\section{References}

Ang, A.H. \& Tang, W.H., 1975. Probability Concepts in Engineering, Planning and Design, Wiley and Sons.

Eurocode, 2004a. EN 1991-2 Traffic load on bridges, CEN.

Eurocode, 2004b. EN 1992 -Design of concrete structures, CEN.

Jacob, B., 2002. Weigh-in-Motion of Axles and Vehicles for Europe (WAVE), General Report, Paris.

Jacob, B., OBrien, E.J. \& Jehaes, S. (Editors, 2002. Weigh-in-Motion of Road Vehicles: Final Report of the COST 323 Action.

Karoumi, R., O’Brien, E.J. \& Quiligan, M., 2006. Calculating an Influence Line from Direct Measurements, Bridge Engineering, 159 (1)(2), pp.31-34.

Moses, F. \& Verma, P., 1987. Load Capacity Evaluation of Existing Bridges,

O'Brien, E., Znidaric, A. \& Ojio, T., 2008. Bridge weigh-in-motion-Latest developments and applications world wide, Proceedings of the International Conference on Heavy Vehicles HV Paris 2008, pp.25-38.

Sivakumar, B., Ghosn, M. \& Moses, F., 2011, Protocols for collecting and using traffic data in bridge design, NCHRP report No.683, Washington D.C.:Transport Research Board.

Skokandić, D., 2016. STSM Report - Application of B-WIM measurements in assessment of existing road bridges, Zagreb.

Sofistik, 2014. Sofistik Software for Structural Analysis.

Šavor, Z. \& Novak, M.Š., 2015. Procedures for reliability assessment of existing bridges, Journal of the Croatian Association of Civil Engineers, 67(6), pp.557-572.

Wiśniewski, D.F., Casas, J.R. \& Ghosn, M., 2012. Codes for safety assessment of existing bridges-current state and further development, Structural Engineering International: Journal of the International Association for Bridge and Structural Engineering (IABSE), 22(4), pp.552-561.

Žnidarič, A. et al., 2012. Simplified Approach to Modelling Traffic Loads on Bridges, Procedia - Social and Behavioral Sciences, 48, pp.2887-2896.

Žnidarič, A. et al., 2011., SiWIM Bridge Weighing-in-Motion Manual 4th Edition, Ljubljana: ZAG.

Žnidarič, A., Kreslin, M. \& Kalin, J., 2016. Weigh-in-motion and traffic load monitoring. Fact Sheet WG 2-9.

Žnidarič, A., Lavrič, I. \& Kalin, J., 2010. Latest practical developments in the Bridge WIM technology, Proceedings of the Fifth International Conference on Bridge Maintenance, Safety and Management, IABMAS. Philadelphia, USA, pp. 993-1000.

Žnidarič, A., Lavrič, I. \& Kalin, J., Measurements of bridge dynamics with a bridge weigh-in-motion system, 5th International Conference on Weigh-in-Motion (ICWIM5). London.

Žnidarič, A. \& Moses, F., 1997. Structural Safety of Existing Road Bridges, Proceedings of the ICOSSAR 97 conference. Kyoto, pp. 1843-1850.

\section{Acknowledgements}

This article is based upon STSM performed in Slovenian national Building and Civil Engineering Institute under auspices of COST Action TU 1402 Quantifying the Value of Structural Health Monitoring, supported by COST (European Cooperation in Science and Technology). 